\title{
Motion Class Dependency in Observers' Motor Areas Revealed by Functional Magnetic Resonance Imaging
}

\author{
Katrin Sakreida, Ricarda I. Schubotz, Uta Wolfensteller, and D. Yves von Cramon \\ Department of Cognitive Neurology, Max Planck Institute for Human Cognitive and Brain Sciences, 04303 Leipzig, Germany
}

\begin{abstract}
Human and animal data suggest that the mere observation of biological motion activates those premotor areas that also underlie the initiation of the same motion. However, data also indicate that the human premotor cortex (PM), in contrast to the monkey PM, responds not only to the observation of goal-directed (transitive) motion but also to intransitive motion. The present study used functional magnetic resonance imaging to test this hypothesis directly. Participants were presented cycles of intransitive motion specified as belonging to the distal (fingers and mouth), proximal (knee, ankle, elbow, and wrist), or axial (trunk and shoulder) motion class. Attention to motion was behaviorally tested by a forced-choice task on motion acceleration and deceleration. Results revealed extended PM activation for each motion condition. However, direct contrasts showed that the most significant activations were elicited in ventrolateral PM by distal motion, in dorsolateral PM by proximal motion, and medial PM (supplementary motor area) by axial motion. Findings confirm observed intransitive motions to engage premotor areas along a gross-scaled somatotopy.
\end{abstract}

Key words: premotor; somatotopy; distal; proximal; axial; functional magnetic resonance imaging; fMRI

\section{Introduction}

The somatotopical organization of primary motor cortex (MI) has become a popular field of research, particularly since the initial discovery of Penfield's homunculus and Woolsey's simiusculus (Penfield and Boldrey, 1937; Penfield and Rasmussen, 1950; Woolsey, 1958). A new field of research is the putative somatotopy in non-primary motor cortices, particularly lateral and medial premotor areas. Monkey studies suggest a premotor cortex (PM) somatotopy approximately parallel to that in MI, except that representational multiplicity and overlap appear to be greater than in MI (Gentilucci et al., 1988; Preuss and GoldmanRakic, 1989; Godschalk et al., 1995). A meta-analysis on human imaging research on this issue appears to confirm a gross PM somatotopy (Schubotz and von Cramon, 2003).

Because overt motor performance is known to hamper functional magnetic resonance imaging (fMRI) data, an important finding was that PM can be activated by mere imagination or observation of motion (Jeannerod and Frak, 1999). Observation instructions promise to be a particularly elegant method to investigate PM without the involvement of MI, which often (albeit inconsistently across studies) lights up when participants are instructed to imagine themselves moving a body part (Leonardo et al., 1995; Sabbah et al., 1995; Porro et al., 1996; Roth et al., 1996; Lotze et al., 1999). So far, however, PM somatotopy has rarely

Received 0ct. 7, 2004; revised Dec. 9, 2004; accepted Dec. 19, 2004.

We thank Andrea Gast-Sandman, Kerstin Flake, and Stefan Hetzer for support in preparing the stimulus material, Bettina Johst for support in programming, Shirley-Ann Rüschemeyer for proofreading and suggestions, and Stefan Zyssett for support in MRI statistics.

Correspondence should be addressed to Katrin Sakreida, Department of Cognitive Neurology, Max Planck Institute for Human Cognitive and Brain Sciences, P.0. Box 500 355, 04303 Leipzig, Germany. E-mail: sakreida@cbs.mpg.de.

DOI:10.1523/JNEUROSCI.4170-04.2005

Copyright $\odot 2005$ Society for Neuroscience $\quad 0270-6474 / 05 / 251335-08 \$ 15.00 / 0$ been addressed using observation tasks. Two fMRI studies have focused on passive observation of motion performed with the mouth, hand, or leg (Buccino et al., 2001; Wheaton et al., 2004). However, whereas Buccino and coworkers report a somatotopy including ventral and dorsal premotor areas bilaterally, Wheaton and coworkers report a somatotopical pattern restricted to the right ventral PM. This divergence may be attributable to several differences in the experimental designs and materials. For instance, both studies differed with respect to the type of movements presented, with the former showing goal-directed (so-called transitive) motion, or movies mimicking the same goal-directed motion without an object, whereas the latter showed non-goal-directed (so-called intransitive) motion. The observation of intransitive motion has been suggested recently to be sufficient in triggering PM activation in humans (Fadiga et al., 1995), although this effect has not yet been reported in monkeys (Rizzolatti et al., 2001).

Finally, previous studies on motion observation presented either distal motion, which is distant and more independent from the trunk, or proximal motion, which is performed with limbs closer to the trunk. However, no study to date has investigated the third motion class, namely axial motion, which is related to movement of the trunk (i.e., hips and shoulders). Patient studies would suggest axial motion to elicit activation within the supplementary motor area (SMA) (Wiesendanger et al., 1973).

The present study investigated PM somatotopy during observation of intransitive distal, proximal, and axial motion. Two hypotheses were tested: (1) ventrolateral PM (PMv) is involved in the representation of observed distal motions rather than observed proximal ones, whereas the opposite is true for the dorsolateral PM (PMd); and (2) SMA is involved in the representation of observed axial motion rather than in observed distal and proximal motion. 
Table 1. Body part movements used as stimulus material (two representative movements were presented for each effector)

\begin{tabular}{ll}
\hline Body part & Movements \\
\hline Distal motion & \\
Fingers & Precision grip; spreading \\
Mouth & Opening and closing; blowing \\
Proximal motion & \\
Knee & Flexion and extension; rotation \\
Ankle & Dorsal and palmar flexion; rotation \\
Elbow & Flexion and extension; rotation \\
Wrist & Dorsal and palmar flexion; rotation \\
Axial motion & \\
Trunk & Sideward bending; rotation \\
Shoulder & Abduction and adduction; rotation \\
\hline
\end{tabular}

To test these assumptions, we used movies showing repetitive cycles of human intransitive motion. Previous applications of the serial prediction task paradigm (Schubotz, 1999) have demonstrated that attending to repetitive sequential stimuli is sufficient to induce activation of PM. Moreover, because attention has been shown to have significant influence on PM activation (Rizzolatti et al., 1987), we also expected this task to yield more powerful activation in PM regions than mere passive observation.

\section{Materials and Methods}

Participants. Nineteen right-handed, healthy young volunteers (10 female, 9 male; age range, 20-33 years; mean age, 25.9 years) participated in the study. All of them had normal or corrected-to-normal visual acuity. After being informed about potential risks and screened by a physician of the institution, subjects gave informed consent before participating. The experimental standards were approved by the local ethics committee of the University of Leipzig. Data were handled anonymously.

Stimuli. A motion observation task was used showing complete continuously repeated cycles of intransitive motion, mostly flexion, extension, or rotation, of one of eight different distal, proximal, and axial body parts (fingers, mouth, knee, ankle, elbow, wrist, trunk, and shoulder) (Table 1) in a random-trial design. For each of these motor effectors, one of two possible motions could be presented. For an exemplary trial progress, see Figure 1. One cycle of motion consisted of 12 frames, which were successively presented such that a smooth motion was perceived. In half of the trials, the 12 frames of each motion cycle were presented for $100 \mathrm{~ms}$ each, such that the perceived motion had a consistent speed. In the other half of the trials, frames of the last motion cycle were presented first longer and than shorter or vice versa, such that the perceived motion slightly accelerated or decelerated at the end of the presentation phase (trial). Acceleration was induced by first scaling up und then scaling down the presentation duration of each motion frame (Fig. 1). Conversely, deceleration was induced by first scaling down and then scaling up the presentation duration of each motion frame. Within each trial, one cycle was consecutively presented four times, preceded by a visual cue ("MOTION") at the beginning, and followed by a question mark that served as a go-signal to administer the response according to the instruction. Subsequently, a visual response feedback was given (plus sign indicated the correct answer, and minus sign indicated the wrong answer).

Visual stimuli were presented with VisuaStim XGA (Resonance Technology, Northridge, CA), over two small thin-film transistor monitors placed directly in front of the eyes, simulating a distance to a normal computer monitor of $1.2 \mathrm{~m}$.

Task instructions. Participants were instructed to attend to the motion cycles and to indicate in a forced-choice mode whether or not observed motions had a consistent speed until the end of the trial by pressing a button after each trial. If a change in velocity was detected, participants were asked to press button 1 with the right index finger, whereas if speed remained constant, participants were asked to press button 2 with the right middle finger. Trials were presented in pseudorandomized order. Twenty-four trials were presented per effector ( 12 of movement 1 and 12 of movement 2). Each trial lasted $7.2 \mathrm{~s}$ at maximum, with the response phase being aborted by the response. Consequently, the intertrial interval was $2.8 \mathrm{~s}$ at minimum. To improve the modeling of the MRI signal, the cue was preceded by a variable jitter time of $0,500,1000$, or $1500 \mathrm{~ms}$. Furthermore, 24 empty trials were used as resting baseline in which participants were instructed to fixate on a small square in the center of the screen.

Data acquisition. Participants were instructed and briefly trained outside the scanner immediately before the MRI session. In the MRI session, subjects were supine on the scanner bed with their right index and middle fingers positioned on the response buttons. To prevent postural adjustments, the subjects' arms and hands were carefully stabilized by tape. In addition, form-fitting cushions were used to prevent arm, hand, and head motion. Participants were provided with earplugs to attenuate scanner noise.

Imaging was performed at $3 \mathrm{~T}$ on a Bruker (Ettlingen, Germany) Medspec 30/100 system equipped with the standard birdcage head coil. Twenty-two axial slices (field of view, $192 \mathrm{~mm}$; $64 \times 64$ pixel matrix; thickness, $4 \mathrm{~mm}$; spacing, $1 \mathrm{~mm}$ ) parallel to the bicommissural line (anterior commissure-posterior commissure) were acquired using a singleshot gradient echo-planar imaging (EPI) sequence (echo time, $30 \mathrm{~ms}$; flip angle, $90^{\circ}$; repetition time, 2 s) sensitive to blood oxygenation leveldependent (BOLD) contrast. Slices were positioned such that they covered the entire premotor region, including SMA. A set of twodimensional anatomical images was acquired for each subject immediately before the functional experiment, using a modified driven equilibrium Fourier transformation (MDEFT) sequence $(256 \times 256$ pixel matrix). In a separate session, high-resolution whole-brain images (160 slices with $1 \mathrm{~mm}$ slice thickness) were acquired from each subject to improve the localization of activation foci using a T1-weighted threedimensional (3D) segmented MDEFT sequence covering the whole brain.

Data analysis. The MRI data were processed using the software package LIPSIA (Lohmann et al., 2001). This software package contains tools for preprocessing, coregistration, statistical evaluation, and visualization of fMRI data. In the preprocessing, functional data were corrected for motion using a matching metric based on linear correlation. To correct for the temporal offset between the slices acquired in one scan, a sincinterpolation based on the Nyquist-Shannon theorem was applied. A temporal high-pass filter with a cutoff frequency of $1 / 80 \mathrm{~Hz}$ (twice the length of one complete oscillation, i.e., minimal gap between two trials of the same condition $=2 \times 40 s \approx 80 \mathrm{~s}$ ) was used for baseline correction of the signal, and a spatial Gaussian filter with $5.65 \mathrm{~mm}$ full-width at halfmaximum (FWHM) was applied. To align the functional data slices with a $3 \mathrm{D}$ stereotactic coordinate reference system, a rigid linear registration with six degrees of freedom (three rotational and three translational) was performed. The rotational and translational parameters of the transformation matrix were acquired on the basis of the MDEFT and EPI-T1 slices to achieve an optimal match between these slices and the individual $3 \mathrm{D}$ reference data set. This $3 \mathrm{D}$ reference data set was acquired for each subject during a previous scanning session. The MDEFT volume data set was standardized to the Talairach stereotactic space [standard brain size, $x=135 \mathrm{~mm}, y=175 \mathrm{~mm}, z=120 \mathrm{~mm}$ (Talairach and Tournoux, 1988)]. The rotational and translational parameters were subsequently transformed by linear scaling to a standard size. The resulting parameters of the normalized transformation matrices were then used to transform the functional slices using trilinear interpolation, so that the resulting functional slices were aligned with the stereotactic coordinate system. Slice gaps were interpolated to generate output data with a spatial resolution of $3 \times 3 \times 3 \mathrm{~mm}$.

The statistical evaluation was based on a least-squares estimation using the general linear model for serially autocorrelated observations (random-effects model) (Friston, 1994; Friston et al., 1995a,b; Worsley and Friston, 1995). The design matrix was generated with a boxcar function, convolved with the hemodynamic response function. For each trial, the epoch length was $4.8 \mathrm{~s}$ and comprised all movement cycles. Only correctly answered trials entered the analysis. The effect of motor response was controlled for by balancing the type and number of required motor responses between all contrasted conditions. The model equation, 

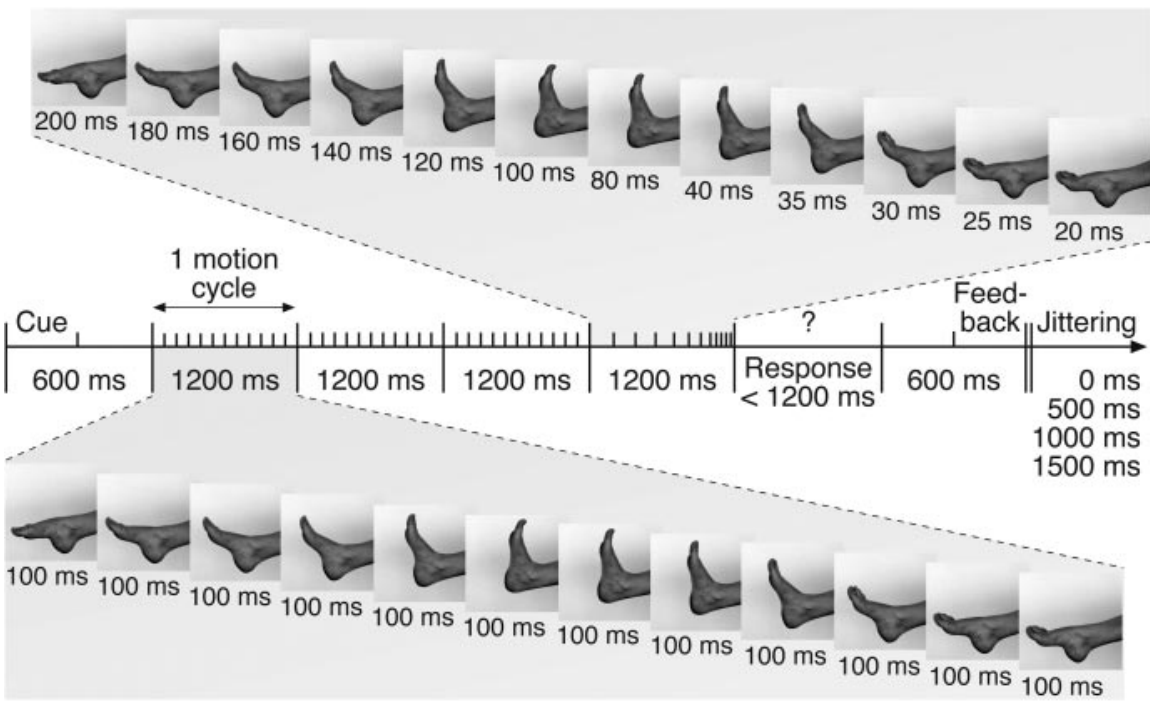

Figure 1. Exemplary trial for the observation of proximal motion (here ankle). The bottom extraction shows a regular, i.e., constant, perpetuated motion cycle of a dorsal and palmar flexion. This motion is subsequently repeated two additional times. The top extraction shows the last repetition of this motion. Here, the time scale shows that motion is slightly accelerated at the end. Immediately after movie presentation, participants were required to indicate by button press whether or not they perceived such a violation of the velocity pattern.

including the observation data, the design matrix, and the error term, was convolved with a Gaussian kernel of dispersion of $4 \mathrm{~s}$ FWHM to deal with the temporal autocorrelation (Worsley and Friston, 1995). In the following, contrast images, i.e., estimates of the raw-score differences between specified conditions, were generated for each participant. As noted previously, each individual functional dataset was aligned with the standard stereotactic reference space, so that a group analysis based on the contrast images could be performed. Subsequently, the single-subject contrasts were entered into a second-level random-effects analysis for each of the contrasts. The group analysis consisted of a one-sample $t$ test across the contrast images of all subjects that indicated whether observed differences between conditions were significantly distinct from zero. Subsequently, $t$ values were transformed into $Z$ scores. To protect against falsepositive activations, only regions with $Z$ score $>3.09$ ( $p<0.001$; uncorrected) and with a volume $>135 \mathrm{~mm}^{3}$ (five contiguous voxels) were considered (Forman et al., 1995). Local maxima of the $Z$ maps are listed in Table 2. A voxel was defined to be a local maximum if its $Z$ value exceeded 3.09 and if it was largest within a $12 \mathrm{~mm}$ radius. Local maxima residing in activation areas of size smaller than $135 \mathrm{~mm}^{3}$ are not reported. Figure 3 (bottom panel) shows the resulting $Z$ maps overlaid onto an anatomical reference image.

Regions of interest (ROIs) comprised the maximally activated voxel for distal compared with proximal (left and right PMv), for proximal compared with distal (left and right PMd), and axial compared with distal and proximal (left SMA). From each ROI, the individual contrast values were extracted for each motion class (compared with rest) and each participant. Subsequently, these contrast values were subjected to repeated-measures ANOVAs.

\section{Results}

\section{Behavioral results}

Behavioral performance (Fig. 2) was assessed by error rates (mean \pm SE for all conditions, $8.5 \pm 1.8 \%$ ) and reaction times (mean \pm SE for all correctly answered trials, $510 \pm 24 \mathrm{~ms}$ ). Two repeated-measures ANOVAs revealed a significant main effect of the three-level factor MOTIONCLASS (distal, proximal, and axial $)$ on both error rates $\left(F_{(2,36)}=4.2 ; p=0.023\right)$ and reaction time $\left(F_{(2,36)}=12.9 ; p<0.001\right)$. To protect against false-positive results, the significance level for post hoc $t$ tests was adjusted to $p=$ 0.05 (corresponding to uncorrected $p=0.016$ ) by applying Bon- ferroni correction for multiple comparisons (here three). As a result, the differences of error rates between conditions failed to reach the corrected significance threshold (distal vs proximal, $t_{(18)}=2.6$, $p=0.019$; distal vs axial: $t_{(18)}=2.1, p=$ 0.046; proximal vs axial, $t_{(18)}=0.4, p=$ $0.706)$. The reaction times for the distal condition were significantly shorter than those for both the proximal $\left(t_{(18)}=3.0\right.$; $p=0.008)$ and axial $\left(t_{(18)}=4.4 ; p<\right.$ $0.001)$ condition, whereas the differences in reaction times between the proximal and axial condition did not reach the corrected significance threshold $\left(t_{(18)}=2.5\right.$; $p=0.023)$.

\section{fMRI results}

When contrasted with the resting condition, each motion class, i.e., distal (collapsed across fingers and mouth condition), proximal (collapsed across knee, ankle, elbow, and wrist condition), and axial (collapsed across trunk and shoulder condition) revealed extended premotor activation. To test for dominant foci of premotor activation according to our hypotheses, three direct comparisons were calculated: distal versus proximal (d-p), proximal versus distal ( $\mathrm{p}-\mathrm{d})$, and axial versus distal and proximal (a-dp) (Fig. 3, Table 2). Contrast d-p revealed dominant activation within the PMv for monitoring of distal motion, whereas contrast $\mathrm{p}$ - $\mathrm{d}$ revealed dominant activation within the PMd for monitoring of proximal motion. This finding confirmed our first hypothesis, which tested the assumption that PMv is involved in the representation of observed distal motions rather than observed proximal ones, whereas the opposite is true for the PMd. Additional activation was found for observation of distal motion compared with proximal motion within the posterior superior temporal sulcus (pSTS) bilaterally but predominantly within the right hemisphere, within the middle portion of the right intraparietal sulcus, and within the left posterior inferior insula. For the observation of proximal motion compared with distal motion, activation was located within the right superior parietal lobule, within the somatosensory association cortex (postcentral sulcus), and within the occipital gyri, probably corresponding to the extrastriate body area (EBA) (Downing et al., 2001; Grossman and Blake, 2002).

The contrast testing our second hypothesis (a-dp), which assumed that the SMA is involved in the representation of observed axial motion rather than in observed distal and proximal motion, revealed significantly stronger activation for axial compared with distal and proximal motion within the left SMA and PMd, with left PMd showing higher $Z$ scores compared with the right PMd. Note, however, that SMA activation was slightly below statistical threshold $(Z=2.85)$. Additional activation for axial motion observation was located within superior parietal lobule, the paracentral lobule, the EBA, and higher visual areas. Talairach coordinates of maximal activation in left PMd were identical to those reported for the proximal condition, in contrast $\mathrm{d}-\mathrm{p}$. This finding confirmed the first part of our second hypothesis, expecting SMA to show more activation for axial compared with distal and proximal motion observation. However, because we found PMd activation for axial motion observation in addition to hypothesized 
Table 2. Anatomical area, hemisphere, Talairach coordinates $(x, y, z)$, and maximal $Z$ scores of significant activations of the direct contrasts

\begin{tabular}{|c|c|c|c|c|c|}
\hline Anatomical area & Hemisphere & $x$ & $y$ & $z$ & Z \\
\hline \multicolumn{6}{|c|}{ Observation of distal motion versus observation of proximal motion } \\
\hline \multirow[t]{2}{*}{$\mathrm{PMv}$} & $\mathrm{L}$ & -46 & 5 & 21 & 4.13 \\
\hline & $\mathrm{R}$ & 46 & 11 & 23 & 4.56 \\
\hline \multirow[t]{2}{*}{ Posterior inferior insula } & $\mathrm{L}$ & -41 & -4 & -4 & 4.07 \\
\hline & $\mathrm{L}$ & -37 & -19 & -1 & 3.98 \\
\hline \multirow[t]{3}{*}{ pSTS } & $\mathrm{L}$ & -53 & -55 & 12 & 3.72 \\
\hline & $\mathrm{R}$ & 52 & -37 & 6 & 4.73 \\
\hline & $\mathrm{R}$ & 56 & -46 & 20 & 4.26 \\
\hline Intraparietal sulcus & $\mathrm{R}$ & 28 & -52 & 41 & 3.70 \\
\hline \multirow[t]{2}{*}{ Occipital gyri } & $\mathrm{L}$ & -22 & -94 & -6 & 4.47 \\
\hline & $\mathrm{R}$ & 26 & -91 & -3 & 4.35 \\
\hline \multicolumn{6}{|c|}{ Observation of proximal motion versus observation of distal motion } \\
\hline \multirow[t]{2}{*}{ PMd } & $\mathrm{L}$ & -20 & -10 & 53 & 3.56 \\
\hline & $\mathrm{R}$ & 29 & -10 & 52 & 3.34 \\
\hline Primary sensorimotor cortex (SI/MI) & $\mathrm{R}$ & 37 & -16 & 40 & 3.70 \\
\hline \multirow{2}{*}{ Somatosensory association cortex } & $\mathrm{L}$ & -28 & -40 & 55 & 4.07 \\
\hline & $\mathrm{R}$ & 31 & -37 & 55 & 4.52 \\
\hline Superior parietal lobule & $\mathrm{R}$ & 10 & -61 & 53 & 3.64 \\
\hline \multirow[t]{2}{*}{ Occipital gyri (EBA) } & $\mathrm{L}$ & -37 & -73 & 14 & 4.04 \\
\hline & $\mathrm{R}$ & 41 & -70 & 9 & 4.19 \\
\hline Calcarine sulcus & $\mathrm{R}$ & 5 & -82 & 8 & 5.10 \\
\hline \multirow[t]{2}{*}{ Cuneus } & $\mathrm{L}$ & -10 & -91 & 29 & 4.11 \\
\hline & $\mathrm{R}$ & 16 & -85 & 29 & 4.46 \\
\hline \multicolumn{6}{|c|}{ Observation of axial motion versus observation of distal and proximal motion } \\
\hline SMA & $\mathrm{L}$ & -4 & -13 & 56 & $2.85^{*}$ \\
\hline PMd & $\mathrm{L}$ & -20 & -7 & 50 & 4.04 \\
\hline Paracentral lobule & $\mathrm{R}$ & 10 & -28 & 44 & 3.12 \\
\hline Superior parietal lobule & $\mathrm{L}$ & -17 & -49 & 47 & 3.36 \\
\hline \multirow[t]{2}{*}{ Lingual gyrus } & $\mathrm{L}$ & -16 & -73 & -6 & 4.53 \\
\hline & $\mathrm{L}$ & -7 & -67 & 2 & 4.44 \\
\hline \multirow[t]{2}{*}{ Occipital gyri (EBA) } & $\mathrm{L}$ & -38 & -76 & 17 & 3.44 \\
\hline & $\mathrm{R}$ & 40 & -64 & 18 & 3.75 \\
\hline Calcarine sulcus & $\mathrm{R}$ & 7 & -79 & 3 & 4.94 \\
\hline Cuneus & $\mathrm{L}$ & -7 & -79 & 23 & 3.81 \\
\hline \multirow[t]{2}{*}{ Precuneus } & $\mathrm{L}$ & -2 & -82 & 46 & 4.14 \\
\hline & $\mathrm{R}$ & 13 & -79 & 43 & 4.13 \\
\hline \multirow[t]{2}{*}{ Intraparietal sulcus } & $\mathrm{L}$ & -16 & -88 & 34 & 3.58 \\
\hline & $\mathrm{R}$ & 25 & -85 & 27 & 4.30 \\
\hline
\end{tabular}

The asterisk indicates subthreshold activation. L, Left; $\mathrm{R}$, right.

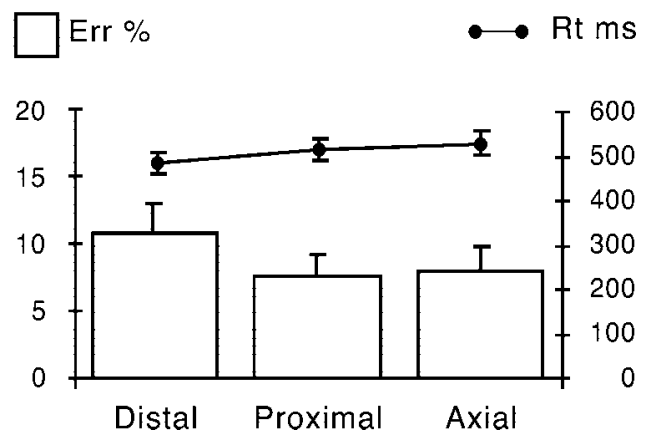

Figure 2. Behavioral data. Bars show the percentage of error rates (Err \%), and lines show the reaction times in milliseconds (Rt $\mathrm{ms}$ ).

SMA, compared with collapsed activation of distal and proximal conditions, we computed two additional contrasts, axial versus proximal motion (a-p) and axial versus distal motion (a-d). These contrasts showed that left and right PMd activation resulted particularly from differences between axial and distal motion observation, whereas this differences was smaller, although significant, for a-p.
To further evaluate the size of BOLD effects, contrast values for each motion class were analyzed in selected ROIs (see Materials and Methods) (Fig. 3, middle panel). According to the first hypothesis, a repeated-measures ANOVA was calculated with the two-level factors ROI (PMv and PMd), CONDITION (distal and proximal), and HEMISPHERE (left and right). We found a main effect for CONDITION $\left(F_{(1,18)}=6.0 ; p=0.024\right)$, an interaction of ROI by CONDITION $\left(F_{(1,18)}=98.7 ; p<0.001\right)$, and an interaction of ROI by HEMISPHERE $\left(F_{(1,18)}=4.5 ; p=0.049\right)$. The ROI by CONDITION interaction was analyzed in more detail according to our first hypothesis using paired $t$ tests. To protect against false-positive results, the significance level was adjusted to $p=0.05$ (corresponding to uncorrected $p=0.013$ ) by applying Bonferroni correction for multiple comparisons (here four). Within PMv, contrast values for distal were significantly higher than those for proximal $\left(t_{(18)}=7.3\right.$; $\left.p<0.001\right)$, whereas the opposite was true in $\mathrm{PMd}\left(t_{(18)}=5.3 ; p<0.001\right)$. As depicted in Figure 3, this held for both hemispheres (distal $>$ proximal in left $\mathrm{PMv}, t_{(18)}=5.2, p<0.001$; right PMv, $t_{(18)}=6.6, p<0.001$; proximal $>$ distal in left PMd, $t_{(18)}=4.6, p<0.001$; right $\mathrm{PMd}$, $\left.t_{(18)}=4.0, p=0.001\right)$.

Analyzing the not hypothesized ROI by HEMISPHERE interaction, we found only one marginal effect, indicating that contrast values for the right PMd were higher than those for the left PMd, independent of condition $\left(t_{(18)}=2.0 ; p=0.062\right)$.

According to the second hypothesis, a repeated-measures ANOVA was calculated with the three-level factor CONDITION (distal, proximal, and axial) in the SMA ROI. We found a main effect for CONDITION $\left(F_{(2,36)}=5.6 ; p=0.008\right)$. Again, the significance level for post hoc $t$ tests was adjusted to $p=0.05$ (corresponding to uncorrected $p=0.016$ ) by applying Bonferroni correction for multiple comparisons (here three). Paired $t$ tests revealed that, within SMA, the contrast values of the axial motion were significantly higher than those of both proximal motion $\left(t_{(18)}=2.8 ; p=0.012\right)$ and distal motion $\left(t_{(18)}=2.8 ; p<\right.$ $0.012)$, whereas values of proximal and distal motion did not $\operatorname{differ}\left(t_{(18)}=0.7 ; p=0.498\right)$.

Because contrasts a-d and p-d had revealed left PMd to be activated both by proximal and axial motion observation, we finally compared contrast values within this ROI for axial and proximal motion. This $t$ test revealed only a marginal effect for axial versus proximal motion $\left(t_{(18)}=1.9 ; p<0.070\right)$.

\section{Discussion}

The present fMRI study investigated whether attentive observation of intransitive body motion induces motion class-dependent activations in lateral PM and SMA. As hypothesized, we found (1) $\mathrm{PMv}$ to be more strongly engaged by the observation of distal motions compared with the observation of proximal motions, whereas the opposite held true for the PMd, and (2) SMA to be more strongly engaged by the processing of axial motion compared with that of distal and proximal motion. Together, findings confirm a gross-scaled somatotopy in premotor areas, dividing secondary motor cortex into three fields preferentially related to different motion classes.

The present study is the first to use an observation paradigm to systematically investigate the entire premotor region including both the lateral and the medial portions. Our findings complement fMRI studies on observed hand, mouth, and leg motion (Buccino et al., 2001; Wheaton et al., 2004). In contrast to these studies, which used a perception instruction, we combined motion observation with an attentionally demanding task, taking into consideration that attention enhances premotor activation 

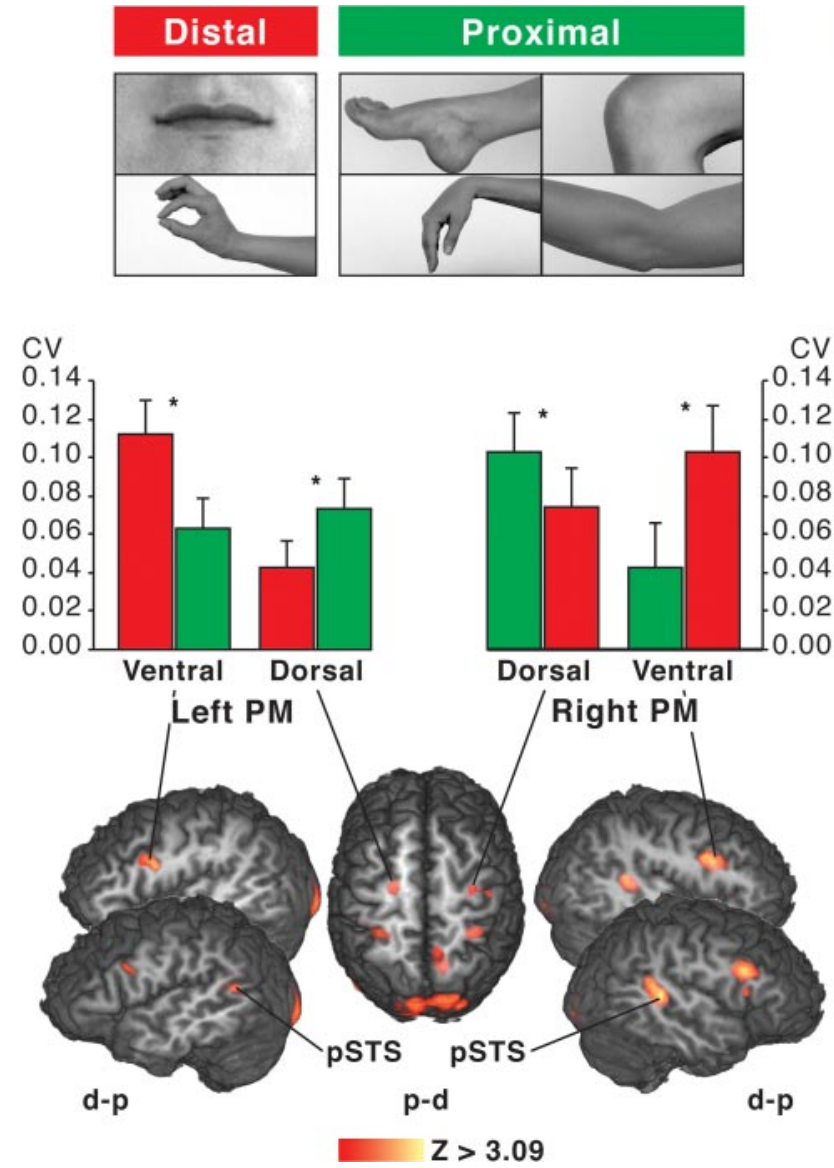

Figure 3. Brain correlates of experimental tasks. Group-averaged $(n=19)$ statistical maps of significantly activated areas for observation of intransitive motion performed by distal, proximal, or axial body parts. Bar charts show the contrast values (CV) in selected ROIs for the distal (red), proximal (green), and axial (blue) motion conditions. Bottom left panel shows the $Z$ map for the direct contrast distal-proximal, thresholded at $Z>3.09$. Observation of distal motion activated PMv within both hemispheres more significantly than observation of proximal motion, whereas the opposite was true for the PMd. Observation of distal motion elicited additional bilateral activation within the pSTS. Bottom right panel shows the Z map for the direct contrast axial-(distal, proximal), thresholded at $Z>2.33$. This contrast showed the SMA to be more consistently engaged for axial motion than for others. This is also evident from the rightmost bar chart in which contrast values are depicted for each motion condition in the SMA ROI.

(Rizzolatti et al., 1987). To this end, participants were required to indicate in a forced-choice mode whether observed motions, presented in several continuously repeated cycles, followed a homogeneous velocity pattern until the end of each presentation phase (trial) or whether motions were subjected to a short and slight acceleration or deceleration. Because participants were required to carefully match the perceived onto an expected pattern of velocity, this task was expected to induce the neural representation of slow closed-loop movements. In contrast to fast openloop movements, these movements require a controlled continuous modification of the motor output according to kinesthetic feedback and have been particularly related to PM activation (Siebner et al., 2001).

The present study hypothesized and found primarily segregated maxima of activation during observation of distal, proximal, and axial motion in PMv, PMd, and SMA, respectively. Particularly, direct contrasts between conditions and corresponding ROI analyses pointed toward centroids of motion classdependent representations. Contrasted with a resting baseline, however, each type of observed motion class elicited extended activation encompassing both lateral PM and SMA. Moreover, both axial and proximal motion were found to engage PMd,

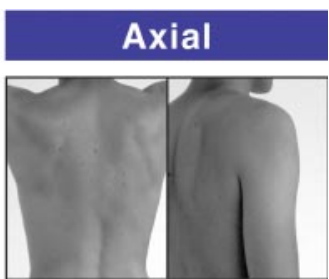

CV
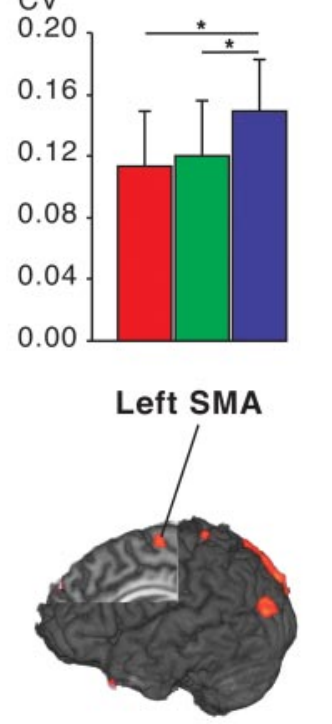

a-dp

$Z>2.33$ suggesting a representational overlap of axial and proximal motion observation correlates in this area.

Overall, the data presented here fit very well into the account of an observable but limited somatotopy in frontal motor cortices. Favoring functional rather than body surface organization criteria for the primary motor cortex, Schieber (2001) suggests that the degree of somatotopic segregation in MI may parallel the biomechanical independence of different body parts. According to this idea, the thumb, for instance, is mechanically independent from the lips, and so are their representations in motor cortices, whereas interdependency and hence representational overlap is substantial between thumb and other fingers. This rationale may be even more plausible for non-primary motor cortices, because they are suggested to especially serve multi-joint movements (Luppino et al., 1991), which involve biomechanically interdependent joints. However, animal data demonstrate that somatotopical maps of the lateral PM lie in approximate correspondence to that of M1, with a forelimb and hindlimb representation in PMd and an orofacial and forelimb representation within PMv (Hast et al., 1974; Kurata et al., 1985; Kurata and Tanji, 1986; Gentilucci et al., 1988; Rizzolatti et al., 1988; Kurata, 1989; He et al., 1993; Hepp-Reymond et al., 1994; Preuss et al., 1996; Graziano and Gandhi, 2000; Yoshino et al., 2000). Premotor projections to M1 hence appear to respect the somatotopy of the target area, with horizontally organized projections slightly inclining from rostroventral to caudodorsal (Matsumura and Kubota, 1979; Muakkassa and Strick, 1979; Godschalk et al., 1984; Matelli et al., 1986; Dum and Strick, 1991; Luppino et al., 1993).

So far, no direct and comprehensive investigation of premotor somatotopy, combining motion paradigms and imaging methods, has been conducted. However, a number of single imaging studies dedicated to the investigation of hand, foot, and face motion contribute to the account of a gross-scaled body representation encompassing both primary and secondary motor cortices, as summarized in a recent meta-analysis (Schubotz and von Cramon, 2003). This overview shows that premotor activations for distal motion reside in the ventral portion of PM and are distinct from more dorsally located activations for proximal motion. Correlates of hand motion were more distributed across the middle portion of PM convexity. Interestingly, as summarized in the same overview paper, this dichotomy is paralleled by tasks in which participants do not have to move themselves but rather imagine or observe these types of movements. Together, these studies suggest that execution is not mandatory to induce execution-equivalent activations in PM (Jeannerod, 2001).

Interestingly, observation of tools has been found to engage a PMv area highly similar to the one we report for distal motion observation in the present study (Grafton et al., 1997; 
Beauchamp et al., 2003). Premotor activation in response to tool perception has been proposed to reflect human experience in grasping and manipulating tools (Chao et al., 2002). These findings fit very well together, because grasping and manipulating are prime examples for complex distal motion. It has to be considered, however, that tool use involves proximal motion in addition to distal motion. This implies a stricter neuroanatomical correspondence between tool observation and distal motion compared with that between tool observation and proximal motion. A potential explanation may relate to the fact that distal motions are strongly guided by the grasped or manipulated object. In support of this notion, a large portion of monkey PMv neurons (so-called canonical neurons) were reported to be tuned to both the sight of objects and the corresponding object grip type (Murata et al., 1997). Hence, a close correspondence between PMv activation for distal motion observation and for tool observation may reflect activity of neuronal populations with a preference for both.

Axial motion or postural adjustments, in contrast, have not yet been investigated via motion execution using imaging techniques, probably because they would result in large motion artifacts. Surprisingly, there is also no study on imagination or observation of axial movement. Our study therefore appears to be the first to investigate observation of axial motion, operationalized by using movies on intransitive hip and shoulder movements. Finding SMA to be particularly engaged during this task, our results are in line with results from patient studies indicating the SMA to subserve anticipatory postural control associated with a voluntary limb movement (Gurfinkel and Elner, 1973; Wiesendanger et al., 1973; Wiesendanger, 1981; Massion and Dufosse, 1988; Massion et al., 1989; Massion, 1992). Anticipatory postural adjustments, which are subserved by SMA, precede and accompany most movements, particularly bilateral ones, thus establishing the role of the SMA in the preparation of movement in general (Brinkman, 1984; Cunnington et al., 1996). The present findings add to this account, showing SMA to be particularly activated by the attentive observation of hip and shoulder motion of another person.

For the present observation paradigm, we used motion that was not directed toward an object or a place in space. This type of motion is sometimes referred to as intransitive, borrowing the linguistic term that denotes verbs not requiring an accusative object (like "flying" or "running"). However, only the observation of goal-directed or transitive motion, which is considered to be the definition for action in a narrower sense, was found to activate PM in the monkey (Umiltà et al., 2001). Action observation studies in humans suggest that BA 44, possibly including inferiormost BA 6, may be the functional homolog of monkey F5 and code for goals of actions accordingly (Buccino et al., 2004). In contrast to the monkey, however, human PM appears to be responsive to observation of intransitive motion as well. This has been demonstrated recently in a transcranial magnetic stimulation study by Fadiga et al. (1995) in which a significant motor facilitation was demonstrated via enhanced motor-evoked potentials in observers of intransitive arm motion. Trying to characterize those PM responses on observed motion, studies on the $\mathrm{H}$-reflex suggest that activation within motor cortices might reflect an inhibition of imitation tendencies (Baldissera et al., 2001). However, because we used an attentively demanding task, resulting PM correlates of motion observation probably reflect more than an involuntary motor facilitation, such as that described for the mimicking of facial expression (Dimberg et al., 2000). We rather suggest that the task led participants to covertly coproduce observed motion cycles to detect slight deceleration or acceleration. Against this background, one could hypothesize that instruction plays a key role for differences between monkey and man as far as intransitive motion is concerned: for the monkey, observed intransitive motion is mostly irrelevant and may therefore not suffice to induce motor facilitation or active motor imagery; in the human, however, an experimental task instruction of course suffices to engage attention to motion, even if it is intransitive.

In contrast to proximal or axial motion, distal motion induced activation within the pSTS, particularly in the right hemisphere. This region has been related to the perception of biological motion, as discovered in the monkey (Perrett et al., 1985, 1989) and replicated in humans (Vaina et al., 2001). Finding this area to be particularly activated by sight of finger and mouth movements, in contrast to that of other body parts, nicely replicates the finding that these movements generate particularly robust neural responses, possibly attributable to their special importance in social interactions (Campbell et al., 1990; Heywood and Cowey 1992; Puce and Perrett, 2003). Additional condition-specific activations were located within different somatosensory areas, including the central sulcus (referring to primary somatosensory or motor cortex) and the somatosensory association cortex (postcentral sulcus) for observation of proximal compared with distal motion and the posterior insula for distal compared with proximal motion observation. These areas are known to be related to tactile sensation and/or tactile attention (for review, see Burton, 2002). The present findings hence demonstrate that a visual task that requires attention to observed body motion suffices to engage somatosensory cortices.

\section{Conclusion}

The present fMRI study shows that somatotopic representations within entire human PM can be elicited by an attentionally demanding motion observation task. Motion class-dependent significant activations according to intransitive (i.e., non-goaldirected) distal, proximal, and axial body part motion were arranged in a gross-scaled manner, with segregated activation foci for distal motion within ventrolateral PM, for proximal motion within dorsolateral PM, and for axial motion within the medial PM (SMA), respectively. Findings support an observable but limited somatotopy in frontal motor cortices.

\section{References}

Baldissera F, Cavallari P, Craighero L, Fadiga L (2001) Modulation of spinal excitability during observation of hand actions in humans. Eur J Neurosci 13:190-194.

Beauchamp MS, Lee KE, Haxby JV, Martin A (2003) FMRI responses to video and point-light displays of moving humans and manipulable objects. J Cognit Neurosci 15:991-1001.

Brinkman C (1984) Supplementary motor area of the monkey's cerebral cortex: short- and long-term deficits after unilateral ablation and the effects of subsequent callosal section. J Neurosci 4:918-929.

Buccino G, Binkofski F, Fink GR, Fadiga L, Fogassi L, Gallese V, Seitz RJ, Zilles K, Rizzolatti G, Freund HJ (2001) Action observation activates premotor and parietal areas in a somatotopic manner: an fMRI study. Eur J Neurosci 13:400-404.

Buccino G, Binkofski F, Riggio L (2004) The mirror neuron system and action recognition. Brain Lang 89:370-376.

Burton H (2002) Cerebral cortical regions devoted to the somatosensory system: results from brain imaging studies in humans. In: The somatosensory system: deciphering the brain's own body image (Nelson RJ, ed), pp 27-72. New York: CRC.

Campbell R, Heywood CA, Cowey A, Regard M, Landis T (1990) Sensitivity to eye gaze in prosopagnosic patients and monkeys with superior temporal sulcus ablation. Neuropsychologia 28:1123-1142. 
Chao LL, Weisberg J, Martin A (2002) Experience-dependent modulation of category-related cortical activity. Cereb Cortex 12:545-551.

Cunnington R, Iansek R, Thickbroom GW, Laing BA, Mastaglia FL, Bradshaw JL, Phillips JG (1996) Effects of magnetic stimulation over supplementary motor area on movement in Parkinson's disease. Brain 119:815-822.

Dimberg U, Thunberg M, Elmehed K (2000) Unconscious facial reactions to emotional facial expressions. Psychol Sci 11:86-89.

Downing PE, Jiang Y, Shuman M, Kanwisher N (2001) A cortical area selective for visual processing of the human body. Science 293:2470-2473.

Dum RP, Strick PL (1991) The origin of corticospinal projections from the premotor areas in the frontal lobe. J Neurosci 11:667-689.

Fadiga L, Fogassi L, Pavesi G, Rizzolatti G (1995) Motor facilitation during action observation: a magnetic stimulation study. J Neurophysiol 73:2608-2611.

Forman SD, Cohen JD, Fitzgerald M, Eddy WF, Mintun MA, Noll DC (1995) Improved assessment of significant activation in functional magnetic resonance imaging (fMRI): use of a cluster-size threshold. Magn Reson Med 33:636-647.

Friston KJ (1994) Statistical parametric mapping. In: Functional neuroimaging: technical foundations (Thatcher RW, Hallet M, Zeffiro T, John ER, Huerta M, eds), pp 79-93. San Diego: Academic.

Friston KJ, Holmes AP, Poline JB, Grasby PJ, Williams SCR, Frackowiak RSJ, Turner R (1995a) Analysis of fMRI time-series revisited. NeuroImage 2:45-53.

Friston KJ, Holmes AP, Worsley KJ, Poline JP, Frith CD, Frackowiak RSJ (1995b) Statistical parametric maps in functional imaging: a general linear approach. Hum Brain Mapp 2:189-210.

Gentilucci M, Fogassi L, Luppino G, Matelli M, Camarda R, Rizzolatti G (1988) Functional organization of inferior area 6 in the macaque monkey. I. Somatotopy and the control of proximal movements. Exp Brain Res 71:475-490.

Godschalk M, Lemon RN, Kuypers HG, Ronday HK (1984) Cortical afferents and efferents of monkey postarcuate area: an anatomical and electrophysiological study. Exp Brain Res 56:410-424.

Godschalk M, Mitz AR, van Duin B, van der Burg H (1995) Somatotopy of monkey premotor cortex examined with microstimulation. Neurosci Res 23:269-279.

Grafton ST, Fadiga L, Arbib MA, Rizzolatti G (1997) Premotor cortex activation during observation and naming of familiar tools. NeuroImage 6:231-236.

Graziano MS, Gandhi S (2000) Location of the polysensory zone in the precentral gyrus of anesthetized monkeys. Exp Brain Res 135:259-266.

Grossman ED, Blake R (2002) Brain areas active during visual perception of biological motion. Neuron 35:1167-1175.

Gurfinkel VS, Elner AM (1973) On two types of static disturbances in patients with local lesions of the brain. Agressologie 14D:65-72.

Hast MH, Fischer JM, Wetzel AB, Thompson VE (1974) Cortical motor representation of the laryngeal muscles in Macaca mulatta. Brain Res 73:229-240.

He SQ, Dum RP, Strick PL (1993) Topographic organization of corticospinal projections from the frontal lobe: motor areas on the lateral surface of the hemisphere. J Neurosci 13:952-980.

Hepp-Reymond MC, Husler EJ, Maier MA, Ql HX (1994) Force-related neuronal activity in two regions of the primate ventral premotor cortex. Can J Physiol Pharmacol 72:571-579.

Heywood CA, Cowey A (1992) The role of the "face-cell" area in the discrimination and recognition of faces by monkeys. Philos Trans R Soc Lond B Biol Sci 335:31-38.

Jeannerod M (2001) Neural simulation of action: a unifying mechanism for motor cognition. NeuroImage 14:103-109.

Jeannerod M, Frak V (1999) Mental imaging of motor activity in humans. Curr Opin Neurobiol 9:735-739.

Kurata K (1989) Distribution of neurons with set- and movement-related activity before hand and foot movements in the premotor cortex of rhesus monkeys. Exp Brain Res 77:245-256.

Kurata K, Tanji J (1986) Premotor cortex neurons in macaques: activity before distal and proximal forelimb movements. J Neurosci 6:403-411.

Kurata K, Okano K, Tanji J (1985) Distribution of neurons related to a hindlimb as opposed to forelimb movement in the monkey premotor cortex. Exp Brain Res 60:188-191.

Leonardo M, Fieldman J, Sadato N, Campbell G, Ibanez V, Cohen L, Deiber
M-P, Jezzard P, Pons T, Turner R, Le Bihan D, Hallet M (1995) A functional magnetic resonance imaging study of cortical regions associated with motor task execution and motor ideation in humans. Hum Brain Mapp 3:83-92.

Lohmann G, Müller K, Bosch V, Mentzel H, Hessler S, Chen L, Zysset S, von Cramon DY (2001) LIPSIA— a new software system for the evaluation of functional magnetic resonance images of the human brain. Comput Med Imaging Graph 25:449-457.

Lotze M, Montoya P, Erb M, Hulsmann E, Flor H, Klose U, Birbaumer N, Grodd W (1999) Activation of cortical and cerebellar motor areas during executed and imagined hand movements: an fMRI study. J Cognit Neurosci 11:491-501.

Luppino G, Matelli M, Camarda RM, Gallese V, Rizzolatti G (1991) Multiple representations of body movements in mesial area 6 and the adjacent cingulate cortex: an intracortical microstimulation study in the macaque monkey. J Comp Neurol 311:463-482.

Luppino G, Matelli M, Camarda R, Rizzolatti G (1993) Corticocortical connections of area F3 (SMA-proper) and area F6 (pre-SMA) in the macaque monkey. J Comp Neurol 338:114-140.

Massion J (1992) Movement, posture and equilibrium: interaction and coordination. Prog Neurobiol 38:35-56.

Massion J, Dufosse M (1988) Coordination between posture and movement: why and how? News Physiol Sci 3:88-93.

Massion J, Viallet F, Massarino R, Khalil R (1989) The supplementary motor area is implicated in the coordination between posture and movement in man. C R Acad Sci III 308:417-423.

Matelli M, Camarda R, Glickstein M, Rizzolatti G (1986) Afferent and efferent projections of the inferior area 6 in the macaque monkey. J Comp Neurol 251:281-298.

Matsumura M, Kubota K (1979) Cortical projection to hand-arm motor area from post-arcuate area in macaque monkeys: a histological study of retrograde transport of horseradish peroxidase. Neurosci Lett 11:241-246.

Muakkassa KF, Strick PL (1979) Frontal lobe inputs to primate motor cortex: evidence for four somatotopically organized "premotor" areas. Brain Res 177:176-182.

Murata A, Fadiga L, Fogassi L, Gallese V, Raos V, Rizzolatti G (1997) Object representation in the ventral premotor cortex (area F5) of the monkey. J Neurophysiol 78:2226-2230.

Penfield W, Boldrey E (1937) Somatic motor and sensory representation in the cerebral cortex of man as studied by electrical stimulation. Brain 60:389-443.

Penfield W, Rasmussen T (1950) The cerebral cortex of man. A clinical study of localization of function. New York: MacMillan.

Perrett DI, Smith PA, Mistlin AJ, Chitty AJ, Head AS, Potter DD, Broennimann R, Milner AD, Jeeves MA (1985) Visual analysis of body movements by neurones in the temporal cortex of the macaque monkey: a preliminary report. Behav Brain Res 16:153-170.

Perrett DI, Harries MH, Bevan R, Thomas S, Benson PJ, Mistlin AJ, Chitty AJ, Hietanen JK, Ortega JE (1989) Frameworks of analysis for the neural representation of animate objects and actions. J Exp Biol 146:87-113.

Porro CA, Francescato MP, Cettolo V, Diamond ME, Baraldi P, Zuiani C, Bazzocchi M, di Prampero PE (1996) Primary motor and sensory cortex activation during motor performance and motor imagery: a functional magnetic resonance imaging study. J Neurosci 16:7688-7698.

Preuss TM, Goldman-Rakic PS (1989) Connections of the ventral granular frontal cortex of macaques with perisylvian premotor and somatosensory areas: anatomical evidence for somatic representation in primate frontal association cortex. J Comp Neurol 282:293-316.

Preuss TM, Stepniewska I, Kaas JH (1996) Movement representation in the dorsal and ventral premotor areas of owl monkeys: a microstimulation study. J Comp Neurol 371:649-676.

Puce A, Perrett DI (2003) Electrophysiology and brain imaging of biological motion. Philos Trans R Soc Lond B Biol Sci 358:435-445.

Rizzolatti G, Riggio L, Dascola I, Umiltà C (1987) Reorienting attention across the horizontal and vertical meridians: evidence in favor of a premotor theory of attention. Neuropsychologia 25:31-40.

Rizzolatti G, Camarda R, Fogassi L, Gentilucci M, Luppino G, Matelli M (1988) Functional organization of inferior area 6 in the macaque monkey. II. Area F5 and the control of distal movements. Exp Brain Res 71:491-507.

Rizzolatti G, Fogassi L, Gallese V (2001) Neurophysiological mechanisms 
underlying the understanding and imitation of action. Nat Rev Neurosci 2:661-670.

Roth M, Decety J, Raybaudi M, Massarelli R, Delon-Martin C, Segebarth C, Morand S, Gemignani A, Decorps M, Jeannerod M (1996) Possible involvement of primary motor cortex in mentally simulated movement: a functional magnetic resonance imaging study. NeuroReport 7:1280-1284.

Sabbah P, Simond G, Levrier O, Habib M, Trabaud V, Murayama N, Mazoyer BM, Briant JF, Raybaud C, Salamon G (1995) Functional magnetic resonance imaging at $1.5 \mathrm{~T}$ during sensorimotor and cognitive tasks. Eur Neurol 35:131-136.

Schieber MH (2001) Constraints on somatotopic organization in the primary motor cortex. J Neurophysiol 86:2125-2143.

Schubotz RI (1999) Instruction differentiates the processing of temporal and spatial sequential patterns: evidence from slow wave activity in humans. Neurosci Lett 265:1-4.

Schubotz RI, von Cramon DY (2003) Functional-anatomical concepts of human premotor cortex: evidence from $\mathrm{PMRI}$ and PET studies. NeuroImage 20 [Suppl 1]:S120-S131.

Siebner HR, Limmer C, Peinemann A, Bartenstein P, Drzezga A, Conrad B (2001) Brain correlates of fast and slow handwriting in humans: a PETperformance correlation analysis. Eur J Neurosci 14:726-736.

Talairach J, Tournoux P (1988) Co-planar stereotaxic atlas of the human brain. New York: Thieme.

Umiltà MA, Kohler E, Gallese V, Fogassi L, Fadiga L, Keysers C, Rizzolatti G
(2001) I know what you are doing: a neurophysiological study. Neuron 31:155-165.

Vaina LM, Solomon J, Chowdhury S, Sinha P, Belliveau JW (2001) Functional neuroanatomy of biological motion perception in humans. Proc Natl Acad Sci USA 98:11656-11661.

Wheaton KJ, Thompson JC, Syngeniotis A, Abbott DF, Puce A (2004) Viewing the motion of human body parts activates different regions of premotor, temporal, and parietal cortex. NeuroImage 22:277-288.

Wiesendanger M (1981) Organisation of secondary motor areas of cerebral cortex. In: Handbook of physiology, Sec 1, The nervous system, Vol II, Motor control (Brooks VB, ed), pp 1121-1147. Bethesda, MD: American Physiological Society.

Wiesendanger M, Séguin JJ, Künzle H (1973) The supplementary motor area-a control system for posture? In: Control of posture and locomotion (Stein RB, Pearson KG, Smith RS, Redford JB, eds), pp 331-346. New York: Plenum.

Woolsey CN (1958) Organization of somatic sensory and motor areas of the cerebral cortex. In: Biological and biochemical bases of behavior (Harlow HF, Woolsey CN, eds), pp 63-81. Madison, WI: University of Wisconsin.

Worsley KJ, Friston KJ (1995) Analysis of fMRI time-series revisitedagain. NeuroImage 2:173-181.

Yoshino K, Kawagishi S, Takatsuki Y, Amano N (2000) Functional properties of the primary motor cortex and ventral premotor cortex in the monkey during a visually guided jaw-movement task with a delay period. Brain Res 852:414-423. 